\section{Multidisciplinary \\ SCIENTIFIC JOURNAL OF MARITIME RESEARCH}

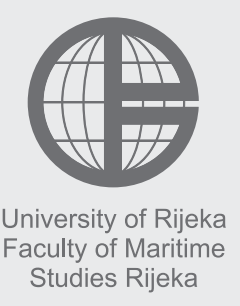

\author{
Multidisciplinarni \\ znanstveni časopis \\ POMORSTVO
}

\title{
About transport costs calculation on the Transsiberial railway
}

\author{
Sergei A. Bykadorov \\ Siberian State Transport University, Novosibirsk. 191 Dusya Kovalchuk Street, Novosibirsk, 630049, Russia, byser@ngs.ru
}

\begin{abstract}
The problem of optimal distribution of train and cargo traffic along parallel lines in the Trans-Siberian transport corridor of the Russian Federation is considered. This problem is closely interconnected with a problem of definition and optimisation of transportation expenses on the Trans-Siberian highway. The economic and mathematical model for determining costs for particular works in each type of line plants (a structural unit) in a railway rather permanent natural labour, material, energy and other norms for transport polygonon are used is offered. This model may serve as the basic part of an automated information system of cost planning on different levels of managing the transportation process.
\end{abstract}

\section{ARTICLE INFO}

Preliminary communication

Received 7 May 2017

Accepted 30 May 2017

Key words:

Trans-Siberian Magistral

Railway Traffic

Transport Costs

\section{Introduction}

Nowadays, the sea carriers occupied the leading position at the world transport market in its inter country sector. They provide transportation of a primary part of cargoes through the Suez and the Panama canal in a triangle of both Americas countries (Northern and Southern) - South East Asia - the European Union. Russia with its overland "transit" potential remains as though away from this transport "mainstream" owing to its traditional transport insufficiency. It can be explained by huge economic undeveloped spaces and transport communications costs. First of all, it refers to the railways which should be necessarily laid, for example, in the Russian Asia, mainly in the extreme natural-climatic conditions.

Railway transport is closely connected with all the branches in a country's economy. Being a natural monopolistic, railway transport is more subject to government regulation than to the other sectors of the economy. On the one hand, it enhances stability of work and ensures sufficient financial support to the sector, on the other hand, it restricts its flexibility and economic and financial sensitivity in its relations with customers due to the difference in the economic and political weight of the partners.

\section{West Siberian railroad}

Considerable extension of the railway network, both on the territory covered and in time demands, perfect matching of the flow of traffic and the transportation cost on each polygon within a given period of time. In each given case transport expenses should be in conformity with the revenues, i.e. transportation rates.

In recent years, the flow of traffic has been on the increase, the existing railroads have been reinforced, the new straightening and supplementary railroads have been built. However, nowadays they turned out to be actually useless, as they add up to the transport expenses, with the flow of traffic having decreased (see table 1, data for 1985-2005 accepted from Basic Indicators of Transport Performances in Russia, 2010; the rest data (expected) - from "Transport Strategy of Russia till 2030" - inertial variant).

Thus, in the '70s-' 80 s, the topical issue for the West Siberian railway was the problem of optimal distribution of rail and cargo traffic along parallel lines (the Transsiberian and the Middle Siberian railways). However, the problem was solved only in the technological aspect, while the economic aspects were not covered. The Middle Siberian railway was built to supplement the Transsiberian railway, as 
Table 1 Freight Turnover By Modes Of Transport (Bln. Tonne-Kilometres)

\begin{tabular}{|l|c|c|c|c|c|c|c|c|c|}
\hline \multicolumn{1}{|c|}{ Modes Of Transport } & $\mathbf{1 9 8 5}$ & $\mathbf{1 9 9 0}$ & $\mathbf{1 9 9 5}$ & $\mathbf{2 0 0 0}$ & $\mathbf{2 0 0 5}$ & $\mathbf{2 0 1 0}$ & $\mathbf{2 0 1 5}$ & $\mathbf{2 0 2 0}$ & $\mathbf{2 0 3 0}$ \\
\hline Railway & 2506 & 2523 & 1214 & 1373 & 1858 & 2344 & 2630 & 21850 & 3050 \\
\hline Road & 277 & 291 & 216 & 153 & 195 & 230 & 260 & 290 & 320 \\
\hline Maritime & 503 & 508 & 284 & 122 & 60 & 85 & 160 & 210 & 300 \\
\hline Inland Waterway & 243 & 214 & 89 & 71 & 87 & 85 & 93 & 104 & 131 \\
\hline Air & 2.7 & 2.6 & 1.0 & 2.5 & 2.8 & 5.2 & 7.6 & 10.1 & 14 \\
\hline
\end{tabular}

the main railway could not cater for the increased volume of traffic, mostly consisting of the transport of coal from the Kuzbass coal basin to the western territories. Later on, the line became a two-lane way and got electrified (see Figure 1).

Currently, as the West Siberian railway has been unified, optimal distribution of workload between the parallel railways has become an important issue again, however, for a totally different reason. Each of the railways can manage with the existing train traffic, but the train traffic has to be distributed in such a way as to minimize the transportation costs, as well as the economic losses and social constraints in the polygons due to the decreased flow of traffic.

In the nearest perspective the volumes of the transport of power producing and raw material cargoes from the
Kuzbass coal basin are expected to grow. However, this is going to take place in a new economic situation, when the railway sector is reformed. And again, optimization tasks associated with the investment efficiency will have to be solved [1].

To our knowledge, similar problems exist in the other sections of the railway network, for example in the Yekaterinburg - Moscow, Yekaterinburg - St. Petersburg directions. Their solution is important not only for the particular railway sector of the economy, but also for the other sectors and RF regions.

The operation of the Transsiberian railway and the Middle Siberian railway parallel to that is in many ways a deciding factor in the development of the domestic transport network. The Transsiberian railway crosses East Siberia and the Russian Far East near the southern bor-

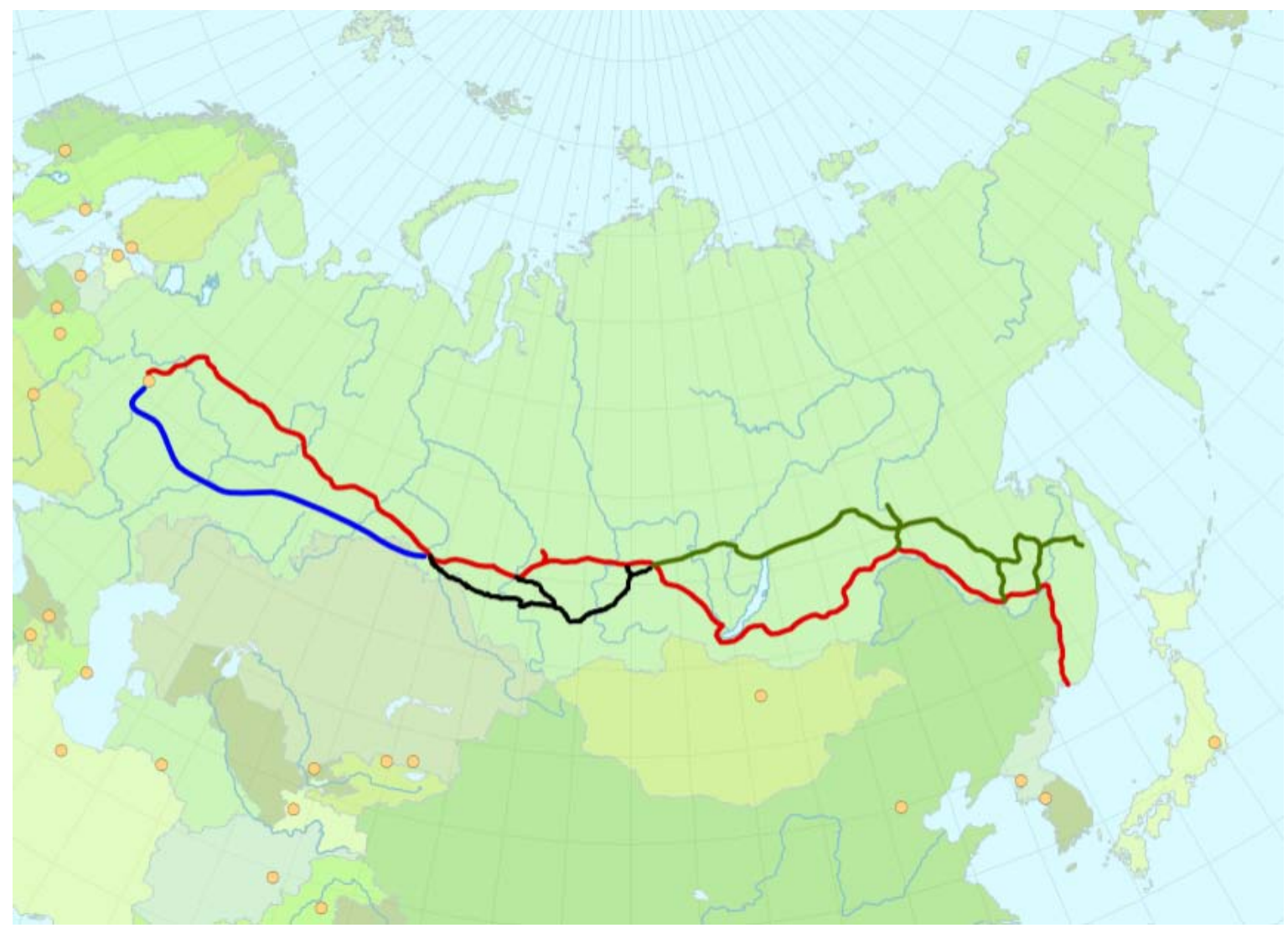

Figure 1 Railways scheme of the Trans-Siberian transport corridor

The red line on a card designates the Trans-Siberian Magistral (a historical route), dark blue - northern route, green - Baikal-Amur highway, black - an interval of a southern way in Siberia (the Middle-Siberian Magistral) 
der of Russia with exits to the ports of Vladivistok and Nakhodka. The Middle Siberian railway goes from Kuzbass to Taishet to merge with the Baikal-Amur railway and the projected crossing from the continent to the Sakhalin Island. In addition to internal transportation, both these lines are to ensure transit freight traffic in combination with the adjoining lines (see Fig. 1).

In the recent several years, the Siberian State University of Transport has been developing a complex system of efficient management of railway transportation based on the optimization of operation costs. The system includes the following interrelated aspects:

- Management of the transportation process in a railway polygonon;

- Management of the operation expenses of the railway industry facilities;

- Systematization and automation of material resources in the railway facilities;

- Studying the effect of restructuring the railway management system on the divisional and network levels.

\section{Research}

The research is being carried out in cooperation with several departments of the Joint Stock Company Russian Railways (http://www.rzd.ru) and the Joint Stock Company Railway Research Institute (JSC "VNIIZhT", http://www. vniizht.ru), its findings being applied in the West Siberian, Krasnoyarsk and Kuibyshev railway divisions.

For a long time, most calculations both on the division railway and the network levels were made using the method of expenditure rates, which is known to be simple to operate and useful for technological and economic calculations. However, the following factors should be taken into consideration:

Firstly, the expenditure rates are as a rule calculated based on the return reports relating to the business and economic activity of different subdivisions of a business. In that, the calculation base includes all the defective operation cases within the periods covered, emergency works, non-productive outlays, as well as "saved resources" due to a shortage of the materials required or breakage or malfunction of the equipment.

Secondly, the calculation of the expenditure rates is based on the outdated technical and technological base of the railways, the structure, age and the development trends which find no reflection in the nomenclature and the values of the expenditure rates.

Thirdly, the expenditure rates do not embrace the changes and the modernization in the technological park, as specifying the expenditure rates by detailed grouping of expenditures and a system of coefficients and even introducing non-linear dependency on meters cannot fully take into account the modern trends in upgrading the patterns of carriage rolling stock and fixed systems.

Standardization of operating costs cannot be based on the data derived from past periods. Consequently, the methods of expenditure rates and their derivatives are absolutely inapplicable for calculations relating not only to the perspective but only to the current periods. For these purposes methods of direct calculation used in planning are to be used.

At the Siberian State University of Transport, research is being carried out to automate calculations and analyse operating costs on the railway polygonon. For this purpose the researchers, in collaboration with the West Siberian railway management, chose linear plants in each section. As input data network and railroad specifications for labour intensity, materials, fuel, electricity, etc., information about work volume and qualitative indices were used. Operating costs were calculated, based on the items of expenses, with as detailed determination of costs of various works, shops and linear plants as possible, using multidimensional economic grids specifications for all kinds of works, expenditure components, types of materials, fuel, etc. Dependent and independent components and expenditures were determined, too.

The significance of the investigation conducted consists in determining a threshold and gradation of sensitivity levels of different linear plants to external factors: the volume of traffic and the number and structure of the technical facilities serviced. It turned out that, in considering linear specifications, staff expenses and linear plant expenditures are exaggerated. That was mostly true for linear plants related to the so-called "passive" fixed assets and accounting for the major part of the independent expenditures: track maintenance departments, signal and communications systems, electrical power supply and stations. Mismatch between the specifications approved and the existing norms for data reaches $22-50 \%$. Very often grouping of expenditures and the set of indices in the nomenclature of expenditure rates and in the branch management documentation do not match, thus adding to a certain confusion and leading to errors in calculations.

Most of the optimization and technological and economic calculations done in the railway branch seem to be based on mismatched existing norms and regulations to the level and the size of volume-and quality-based indices. This is accounted for by the fact that for the purpose of simplifying calculations, a static model of estimation for permanently changing external and internal economic ties in railway transport is used.

Thus, changing the amount of traffic in one of the sections of a railway polygon affects the qualitative indices both of the section considered and of other sections in a complicated way. The financial estimation of this influence with the method of expenditure rates or the method of direct calculations does not give adequate results. This is related to the fact that in each subsequent step of calculations, when one section is changed by another one, the values of norms should change flexibly from one linear plant to another one.

In other words, any calculation related to the optimization of the transportation processes should represent an iterative dynamic process, on each step of which input in- 
formation relating to the situation in the expenditures and technological system should be modified. It is natural that the more detailed the grids-matrices of the input information system are formed, the more sensitive it will be to technological changes and the more optimal parameters in each element of the system will be achieved.

In addition, one measurement method cannot be used to estimate the operation of plants of the same type. Each plant has its unique, i.e. totally different from the others, sets of types of works, organization structure, a system of norms, which cannot be managed quite effectively and adequately even on the level of the Railway Division under, in the modern situation, useful and effective as it might be. On the contrary, to take an effective managerial decision, it is necessary to have maximum possible information regarding the condition of all the subdivisions of all the plants in the polygon considered.

Normally the transportation expenditures are calculated according to a pattern present in the Nomenclature of expenses relating to the basic activity, where they are grouped by items and components of expenditures. In this, expenditures may be traced by the items both in the plans and in the reports. The iterative dynamic model of expenditure calculations allows simulation of various scenarios for project decisions on railway sections, sectors and whole transport polygons.

Expenditure planning for the expenditure component "Materials" is a separate, complex problem, connected with the supply system in the railway transport.

The issues of procuring materials for current repairs and other routine works to be carried out in fixed assets are handled by branch services and the procurement service of the railway management. Different divisions pursue their own interests and use their own groupings and systems of material stock-taking. As a result, different divisions may have in the their balances surplus and shortage of the same materials.

This research should become a basis for developing a data calculation complex for material resources on a railway. The need in resources should be determined based on the volume of traffic and the type of transportation and repair technology.

The traffic of material resources on the railroad will be planned and monitored on the basis of clear regulations and standards used. The process of expenditure movement will be reflected in the corresponding items of the Nomenclature of expenses and in the accounting transactions.

It is impossible to estimate the economic results of the work of a railroad without considering the issue of traffic technologies. The system of economic standards is closely connected with the technologies of train traffic organization, repair and technical maintenance. Moreover, it is necessary to take into account interactions and interference inside the nomenclature of technological norms and types of transport processes and technical support.

The efficiency of the car traffic volume is a major issue of the traffic technology. Until recently, this problem was related only to traffic organization, thus optimization of car formation planning was based primarily on natural showing - time, mileage and power consumption. To be sure, for these purposes it is now necessary to calculate expenses for each component of the railway network pieces of line and stations: costs for each piece of line and station yard expenses, essentially influencing the effectiveness of selecting the directions for car traffic.

A transportation tariff (rate) is one of the basic parameters connecting railway transport with the economic environment, i.e. with the other branches of the national economy. A transport rate level may be a good instrument to evaluate the quality of transportation. Transport rate regulation should on the one hand ensure the make-out of transport operations and, on the other hand, should bring about stability in competition with other types of transport.

The unification process for freight rates is also closely connected with the level of traffic expenses: clarification and flexibility of calculating the traffic expenses may provide an adequate idea of the possible level of transport rates for different conditions of traffic. The issues of rate regulation are interrelated with the issues of inter-industrial price regulation and production balance. However, this broad spectrum of issues requires special research. At present, special importance should be attached to the rate level in mixed transportation for export and import cargo shipped via seaports.

The idea of a system of end-to-end controlling and balance transparency should comprise, in our opinion, both economic and technological planning calculations and planned accounting transactions. Controlling must be based on the internal management accounting. However, management accounting is considered by most practical workers only as registration-oriented, i.e. accounting of the current state of affairs for further analysis and decision-making. Such an attitude is not aimed at enhancing the effectiveness of the economic sector. Controlling and management accounting should be conducted on the level of preliminary planning and research.

Technological changes should be reflected via the items in the Nomenclature of expenses in accounting entries and further in the balance sheet and various forms of appendices attached to it (here not balance sheets proper are meant but their various interim variants). Then these changes may indirectly influence on financial results of various subdivisions and reflect the effectiveness of project decisions not only in the sense of changing expenses for different items of the Nomenclature, but also considering changes in the financial flows in connection with transport units and particular sections and lines.

The proposed approach to budgeting financial flows will allow the actual efficiency of fixed assets and the ways of their optimization to be determined in accordance with the traffic volumes. In addition, objective market evaluation of transport property will further contribute to reduced transport load on the national economy production and simplify liquidation of crossbar financing of cargo and 
passenger transportation, which must raise the attractiveness of private investments in the railway transport.

The proposed system is a more reliable way to optimize restructuring of the railway transport and to separate the monopolistic and the competitive sectors in it.

In the period of developing market relations in an economy, the role of the railway transport as one of the structure-forming branches increases sharply. In Russia, the railway transport is the leading kind of transportation, which is accounted for by the size of the country's territory, varying climatic conditions in the regions, varying population density in different regions, the structural differences in the development of different industries, the long distances between transport partners and the historic conditions under which the country's transport system has developed.

During a long period of time, the railway transport in Russia developed as a centralized sector, and this centralization was, and to a considerable extent still is, higher than in most other sectors of the economy. Alongside with the negative aspects of centralization (lagging behind of the traffic plans from the changing needs of the economy, the inflexible rate policy, etc.), it is important to note its positive aspects, which are to be preserved and "built in" in the market reforms. First of all, it concerns the homogeneity of operating technologies used in the domestic railways, strict safety standards of railway traffic and the experience of monitoring the multifaceted transportation process from one centre on vast territories.

Market reforms would be more effective in the transport, if they were conducted in the period of a large volume of traffic and perspectives for a certain growth. Such a situation in the domestic railways was observed in the late eighties. It was at that time that the research was done aimed to increase the effectiveness of operations and to reduce simple expenditures on railway transportation $[2,3,4]$.

Currently, this research is either stopped or not in demand in this country. However, these studies are being thoroughly studied abroad, in the USA in particular, where the volume of transportation by rail is high enough, while the reserves of the carrying capacity have been exhausted, resulting in a tendency for large railway companies to merge. The patterns of managing the railway sector in Russia and the USA are different, as well as the standards and economic mechanisms. Our countries are at different stages of economic development. However, the similarity of research in the area of railway operation effectiveness conducted and being conducted in the railway transport of Russia (and in former USSR) and the USA suggest that similar problems may have similar solutions [5].

Still, in modern Russia the volume of operations does not correspond to the development level and the amount of the fixed assets in the railway transport. It is for this reason that railway transportation is relatively expensive nowadays and the related expenditures require constant reduction.
Restructuring and reform of the railway transport aimed to reduce transportation costs may fail to bring the result sought, if a mechanism for adequate economic estimation of the projected actions is not developed. For a long time, to estimate different organizational, technical and renovation measures the method of expenditure rates was used, based on grouping the railway and section expenditures for the past period. Such an approach was probably appropriate in a stable economic situation and the constantly growing transportation volumes. Incompatibility of many parameters and averaging of most of the cost norms at that time could be neglected. Only dependent expenditures were considered, and stability of expenditure rates in time was studied. At the time inflation was assumed to be non-existent, while costs were on the decrease.

In the period of decreased transportation volumes, which started in early nineties and which continued until lately, deformation in the ratios between dependent and conditionally fixed expenses was observed. The past periods data ceased to correspond to the future periods data. However, there were no methods of evaluation and analysis except for the method of expenditure rates. It was clear that the expenditure rates for the past periods could not be applied to another time period. In addition, in the period of structural changes, the responsibility borders change and a set of works performed by particular transport plants - depots, railway divisions, stations, railway sections and railways changes too. In other words, expenditure rates have been calculated based on the data of some plants, while their use is required for other plants.

\section{Results}

At present, the railway sector is facing the need of complete restructuring. Not only a change in the responsibility borders, the responsibility areas of structural units and the set of the works performed are to be changed but new types of plants with new internal and external production and economic ties are to be created, as well as the structure of sub-branches of the transport branch has to be modified too [6,7].

Under the given circumstances, in order to provide economic support of the railway reform, it is necessary to have an economic and financial mechanism, not presupposing any expenditure grouping. Certain norms are to be developed with such detailed fragmentation, so that they could be used for any of the supposed versions of the reform.

In the suggested economic and mathematical model for determining costs for particular works in each type of line plants (a structural unit) in a railway rather permanent natural labour, material, energy and other norms are used. These norms may be used in any newly formed production plant, in changing technological processes concerning transportation, organization and maintenance of the equipment [8]. 
The given economic and mathematical model may serve as the basic part of an automated information system (AIS) of cost planning on different levels of managing the transportation process. AIS is transparent enough, which allows calculations to be made, which reflect the influence of technological and operating parameters on the economic and financial figures. As a result, a possibility of tracing quantitative and qualitative characteristics of traffic on cash flows,. appeared

With the assistance of the unit administrator of the suggested automated information system, it is possible to unite line plants of a polygon or, conversely, decentralize them, calculate in an automatic mode natural and cash indices for the newly formed production plants. Similar calculations may be performed for a polygon of a section, a railroad, a region of railroads and even for the whole network viewed in the aspect of a branch and territory.

The given system is useful for building information and an analytical system in investigating different levels of the branch management. It works both from bottom to top and from top to bottom. In the future, the suggested AIS is planned to be used to optimize expenses with the given traffic volume. This can happen by way of targeted automatic selection and data search when a technology or the specialization degree of particular line units are changed, or by way of rationalization of search in an automatic mode of a smaller volume of works to provide the given output.

One of the important components of AIS for planning current costs is automation in analyzing the need in material resources in the plants of a transport polygon. This system should correspond, on one hand, to differentiation of expenses for the types of works and operations of the transportation process (just as in the Nomenclature of expenses for the main type of activity of railways), and, on the other hand, to the network classifier of material and technological resources.

The flows of inventory holdings, as one of the cost items in the expenditures, should be also based on the volume figures of traffic, norms of cost per plant and be adequate to the chosen version of the operating technology and maintenance of the equipment. The expenditures of material resources should be planned for each production item and for each type of works. Otherwise, if expenditures are to be determined as a whole by the type of a resource per structural unit, the influence of the dynamics of work volumes on the corresponding demand for materials will not be reflected. Applying such an approach to determining the necessity in material resources with the strict monitoring of the items of the Nomenclature and the network classifier for material and technological resources, a possibility for automatic preparation of orders for each item and for any period of time appears In addition to other advantages, it ensures the necessary financial transparency.

Under the market conditions it is necessary to revive the transport and economic ties that were severed during the reform period. Due to the reforms in most of the sectors of the economy, the appearance of new branches and the disappearance of the old branches, longterm ties between consumers and suppliers, have been broken. For a long time, budgeting of cargo, train and car traffic volumes was carried out based not on economic but natural (mostly time) criteria. At present, in order to create economically grounded transport ties and to determine rather precisely the transport component in the price of the end product, it is necessary to know the transportation costs for certain sections and sectors and the costs of processing car traffic volumes in the basic railway stations.

This problem is also solved by using the above described economic and mathematical model of determining costs for particular types of works and AIS budgeting of the current expenses. A model of determining station costs is added to the previous one, which included not only traditional expenses kept at the stations, but also the expenses of other plants (in total of all the plants for the basic activity), which take place at the stations. There is a technique, allowing referral of these expenses to fleets, particular tracks and the areas of particular stations. There is also a possibility of using a dynamic model, which allows calculation of specific cost norms (unit rates) for the indicators of the station performance with changing volume, structure, character and direction of car traffic.

\section{Discussion}

The model developed allows adequately and with a high degree of precision to project the economic and financial components for the newly formed operating structures managing the transportation work in the regional and interregional sectors with different kinds of property, as well as to optimize the versions for matching the monopolistic and competitive components of the economy of the railway sector being reformed. The connection of technological, economic and financial factors acting in different sectors allows to influence promptly the economic results of the branch and to create conditions necessary to introduce technological innovations while preserving management centralized.

\section{References}

[1] Boris A. Binkin, Sergey A. Bykadorov, Yevgeny B. Kibalov. Russia as a configurator of a world railway system in the XXI century//InterBering, LLC URL: http://interbering. com/Russia-configurator-railway-XXI/Russia-as-a-configurator-of-a-world-railway-system-in-the-XXI-century.pdf

[2] Livshits V.N. Sistemnyi analiz ekonomicheskikh protsessov na transporte. Moskva: Transport, 1986. - 240 s. (in Russian)

[3] Galaburda V.G. Optimal'noye planirovanie gruzopotokov. Moskva: Transport. 1985. - 256 s. (in Russian)

[4] Ekonomika zheleznodorozhnogo tranporta: Uchebnik dlya vuzov / Pod redaktsiyey I.V. Belova. - Moskva: Transport, 1989. - 351 s. (in Russian) 
[5] Carl D. Martland (MIT), Michael B. Hargrove (AAR). TRACS: A Tool for Track Infrastructure Management. "Infrastructure Planning and Management", Urban Transportation Division / ASCE, Denver, Colorado, USA, June 21-23, 1993. pp. 177-181.

[6] Bykadorov, Sergey A. Track Reforms. Russian Style. - Problems of Economic Transition. Volume 56, Number 3 / July 2013, pp. 34-43.
[7] Bykadorov, S.A., Kibalov, Ye.B., Kin, A.A. On the Development of Railway Structural Reform in Russia. - Region: Economics and Sociology, Allrussian Science Journal, - Novosibirsk, 2015. - \# 4, pp. 162-178.

[8] Bykadorov S.A. Primenenie informatsionnykh tekhnologiy $\mathrm{v}$ upravlenii zatratami na zheleznodorozhnom transporte. Monografiya. Moskva: Zheldorizdat; Novosibirsk: SGUPS, 2001. - 240 s. (in Russian) 